\title{
Idiopathic Pulmonary Fibrosis: Diagnosis and Prognostic Evaluation
}

\author{
Venerino Poletti ${ }^{\mathrm{a}}$ Claudia Ravaglia $^{\mathrm{a}}$ Matteo Buccioli $^{\mathrm{a}}$ Paola Tantalocco $^{\mathrm{a}}$ \\ Sara Piciucchi ${ }^{b}$ Alessandra Dubini $^{c}$ Angelo Carloni $^{d}$ Marco Chilosi $^{\mathrm{e}}$ \\ Sara Tomassetti ${ }^{\mathrm{a}}$ \\ Departments of a Diseases of the Thorax, ${ }^{\mathrm{b}}$ Radiology and ${ }^{\mathrm{C}}$ Anatomic Pathology, Ospedale GB Morgagni, Forlì, \\ ${ }^{\mathrm{d}}$ Department of Radiology, Ospedale Santa Maria, Terni, and ${ }^{\mathrm{e}}$ Department of Anatomic Pathology, Università di \\ Verona, Verona, Italy
}

\section{Key Words}

Idiopathic pulmonary fibrosis - Interstitial pneumonia .

Pulmonary function test $\cdot$ Usual interstitial pneumonia

\begin{abstract}
Idiopathic pulmonary fibrosis (IPF) is the most common type of idiopathic interstitial pneumonia and has a dismal prognosis. Median age at IPF onset is $60-70$ years and it is mainly related to cigarette smoke exposure. Its clinical profile is heterogeneous and different clinical phenotypes are now better defined: familial IPF, slow and rapid progressors, combined pulmonary fibrosis and emphysema, anti-neutrophil cytoplasmic antibodies/microscopic polyangiitis and IPF, and IPF associated with lung cancer. Acute exacerbation associated with rapid functional decline is an event that does not happen infrequently and affects survival. Diagnosis requires a typical usual interstitial pneumonia (UIP) pattern on computed tomography in the appropriate clinical setting or morphological confirmation of the UIP pattern when imaging findings are not characteristic enough. Surgical lung biopsy is the gold standard to obtain valuable information for histological analysis. However, less invasive procedures (transbronchial lung biopsy or even improved transbronchial lung biopsy by cryoprobes) are now under consideration. Prognostic indicators are mainly derived by pulmonary function tests. Recently, staging systems have been proposed.
\end{abstract}

ㄷ) 2013 S. Karger AG, Basel

\section{KARGER}

E-Mail karger@karger.com

www.karger.com/res

\section{Introduction}

Idiopathic pulmonary fibrosis (IPF) is a progressive and often fatal fibrosing interstitial pneumonia of unknown cause that is limited to the lung and associated with the histopathological and/or radiological pattern of usual interstitial pneumonia (UIP) [1]. The fibrotic process that characterizes IPF is commonly considered the result of recurrent injury to the alveolar epithelium followed by uncontrolled proliferation of bronchiolar epithelium and fibroblasts $[2,3]$. The fibrosis could arise from the most mechanically stressed areas of the lung and relentlessly progresses from the peripheral basal parenchyma to the central parenchyma and upper aspects of the lung [4]. The new pathogenetic paradigm on IPF is that it is a complex process characterized by abnormal pneumocyte apoptosis and profound derangement of alveolar renewal more similar to malignant lung disease [2-5]. Indeed, epigenetic and genetic abnormalities, senescence-related processes (such as oncogene-induced senescence or senescence-associated secretory phenotypes), altered cell-to-cell communications, uncontrolled proliferation and abnormal activation of specific signal transduction pathways are biological hallmarks that characterize the pathogenesis of IPF and link this disorder to lung cancer $[5,6]$. 
IPF accounts for $\sim 55 \%$ of lung diseases classified as idiopathic interstitial pneumonias $[1,6]$; it occurs predominantly in older adults, with an increasing incidence and a prevalence of 20.2 men per 100,000 and 13.2 women per 100,000. It has been estimated that approximately 40,000 new patients will be diagnosed with IPF each year in Europe [7-9]. Retrospective longitudinal studies suggest that the median survival of IPF patients is 3-5 years [8-11]. However, the course of IPF is variable, with some patients experiencing long periods of stability while others experience exacerbations or a rapid progressive decline. The median age at IPF onset is 60-70 years [1]. Cigarette smoke is an independent risk factor for IPF, with an odds ratio of 1.58 (95\% confidence interval: 1.27-1.97) and a possible dose-response relationship between tobacco smoking and the risk of IPF [12].

\section{Clinical Heterogeneity of IPF}

IPF occurs in a sporadic form in most instances, but occasionally it can also occur in familial form; familial cases account for $0.5-3.7 \%$ of cases of IPF with up to $19 \%$ of patients reporting a family history significant for interstitial lung disease $[13,14]$. In the literature, familial IPF has previously been defined with various criteria including the following: patients with clinical features compatible with IPF in combination with either compatible highresolution computed tomography (HRCT) findings or histologic evidence of UIP found in lung biopsy specimens in 2 or more family members; in an index case with at least 2 other affected relatives, or as IPF in at least 2 first-degree relatives. While clinical features of sporadic IPF are well defined, regarding familial IPF, the clinical presentation, complications and outcome of patients are still undefined issues and it has yet to be proven whether familial forms of IPF have a particularly different natural history because of genetic influence or other factors. Some publications have compared the clinical features of familial and sporadic IPF patients and there were no distinguishing features apart from a younger mean age at diagnosis in the familial compared with the sporadic groups [15]. This may represent a true younger onset of disease in familial IPF patients, a more rapid progression to clinically overt illness or perhaps a heightened awareness with earlier diagnosis of individuals from affected families. The phenomenon which is characterized by disease onset at an earlier age or a greater disease severity status in successive generations is known as 'genetic anticipation' and it is a widely known characteristic of many diseases with genetic inheritance. Genetic mutations explain part of the IPF cases. IPF in patients presenting with germline mutations in the hTERT and hTR gene associated with the telomerase complex (a ribonucleoprotein holoenzyme that protects the tips of chromosomes from 'erosion' during cell division) introduces criticisms about the IPF definition as in these patients the disease may not be limited to the lung but can involve other organs or structures (liver, bone marrow or hair), too [16]. Furthermore, in histological studies in familial IPF cases, different patterns (UIP, nonspecific interstitial pneumonia, desquamative interstitial pneumonia or even hypersensitivity pneumonitis) have been documented [17], reinforcing the concept that morphology per se is not a dominant element to define the disease.

Selman et al. [18] reported that a subset of sporadic IPF patients, predominantly smoking males, was characterized by a short duration of symptoms with rapid progression to end-stage disease. These patients had a different gene expression signature (rapid progressors). Brown et al. [19] recently showed that there may be a continuous spectrum of improving patient outcomes based on the duration of survival: in this study, the concept that survival begets survival appears endurable. This study is important because it emphasizes the element 'tempo' as an important clinical category. A CT scan may predict slow progression of the disease when honeycomb changes are not detectable, emphysema profusion is low and HRCT scoring of fibrosis is also low [20]. IPF patients with high mast cell density in surgical lung biopsy specimens seem to have a slower decline in forced vital capacity (FVC) [21]. In clinical practice, however, prediction of the rate of decline is not yet possible. Recently, Kahloon et al. [22] reported that patients with anti-heat shock protein $70 \mathrm{IgG}$ autoantibodies have more near-term lung function deterioration and mortality, and $\mathrm{CD} 28$ downregulation on circulating CD4 T cells is associated with a poor prognosis [23].

Patients with an initial diagnosis of IPF occasionally acquire myeloperoxidase anti-neutrophil cytoplasmic antibodies (MPO-ANCA); of these, less than a quarter develop microscopic polyangiitis. The presence of eosinophils in bronchoalveolar lavage (BAL) fluid and low attenuation areas on CT might be predictive of MPO-ANCA-positive conversion [24].

Combined pulmonary fibrosis and emphysema has been recognized as another peculiar phenotype [25]: the coexistence of emphysema usually in the upper lobes and fibrosis in the lower lobes causes a slight decrease in FVC, a significant impairment in diffusing capacity of the lung 
Fig. 1. Survival curve comparing IPF patients without lung cancer and IPF patients that developed lung carcinoma (data from the database of the Department of Diseases of the Thorax, Ospedale GB Morgagni, Forlì, Italy).

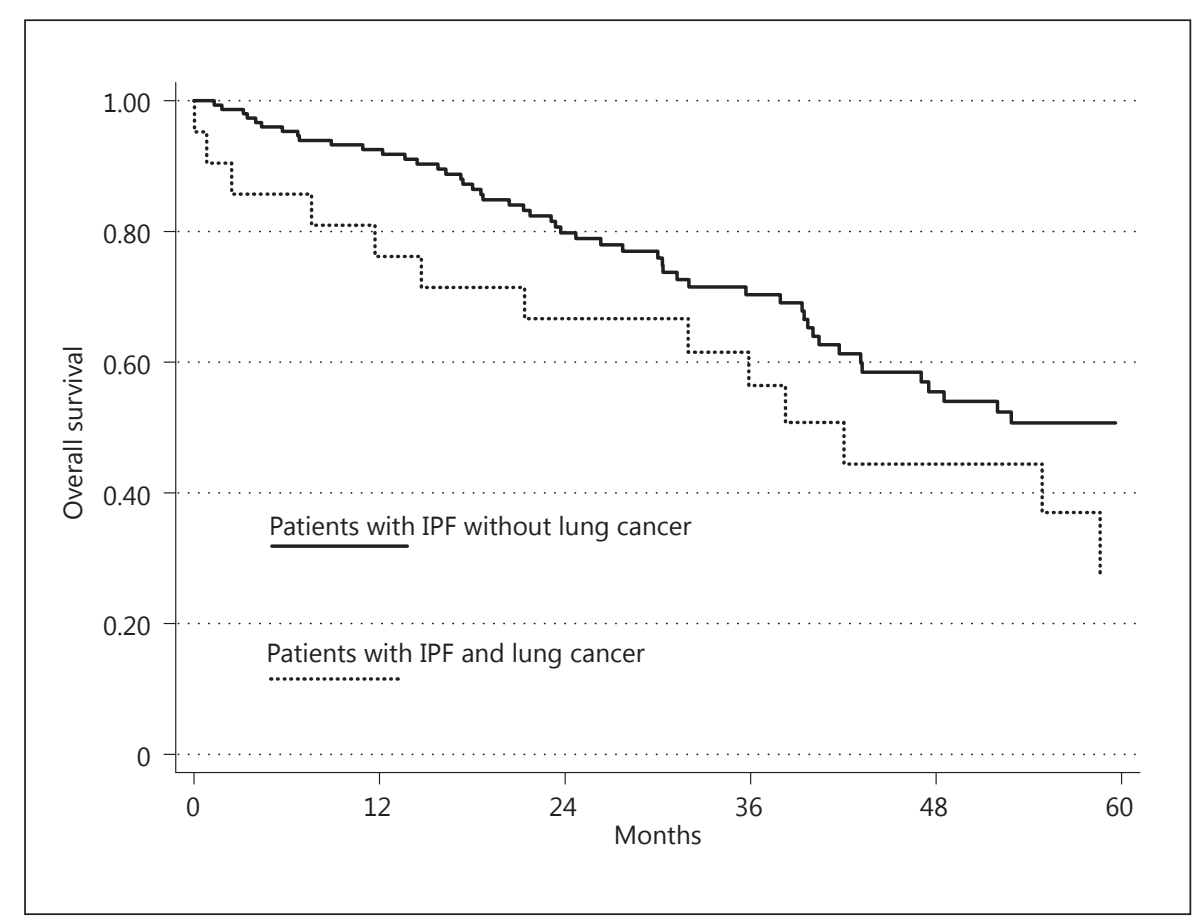

for carbon monoxide (DLCO), exercise hypoxemia and, in the majority of cases, pulmonary hypertension. However, a quantitative definition of emphysema and fibrosis to better define this entity is still missing. The prevalence of pulmonary fibrosis combined with emphysema is about $8 \%$ [26]. This coexistence may be explained by common pathogenetic mechanisms [6].

The incidence of lung carcinoma in IPF patients appears to be significantly increased [27]. The neoplasms are usually peripheral (nodules or masses, rarely alveolar opacification or ground glass attenuation) and reveal peculiar histological phenotypes (squamous carcinoma or adenocarcinoma-enteric type). Survival of patients with lung cancer arising from IPF is shorter than that of patients without cancer (fig. 1); it is still not clear if this depends on the progression of the neoplasm or on the fact that lung carcinoma is more frequent in rapid progressors.

The early phase of IPF is still poorly understood. Kondoh et al. [28] identified 16 patients with IPF without pulmonary function impairment. Seven were asymptomatic. Eleven patients showed physiological disease progression. In this study, both UIP pattern (presence of bibasilar honeycombing) on HRCT and extent of honeycombing were factors associated with disease progression. Detection of the typical 'velcro sounds' on auscultation or accidental detection (in the context of a lung cancer screen- ing program) of bibasilar, subpleural reticular or honeycomb changes are two modalities that could be useful for a precocious diagnosis $[29,30]$.

Acute exacerbation of IPF [31, 32] has become well recognized: it is a rapid deterioration of IPF during the course of the disease that is not due to a particular cause. The 1- and 3-year incidences were reported to be 14.2 and $20.7 \%$, respectively. Nonsmoking and low FVC were recognized as significant risk factors for acute exacerbation [32]. Asymmetrical disease, concomitant emphysema, DLCO $<47 \%$ of predicted, high modified Medical Research Council scale of dyspnea, high body mass index, decline in FVC at 6 months, pulmonary hypertension detected by echocardiogram and surgical pulmonary resection were reported to be other risk factors for acute exacerbation [33-38]; although right heart catheterization is the only definite method to diagnose pulmonary hypertension, increased right ventricular systolic pressure on echocardiogram is suggestive of pulmonary hypertension, and, given the obvious difficulties in performing right heart catheterization in unwell patients, echocardiography is currently the most practical method for assessing pulmonary arterial pressure [34]. Extent of involvement on HRCT and CT patterns are predictive of survival in acute exacerbation of IPF, with worse survival being associated with multifocal and peripheral HRCT patterns [38]. 
Table 1. Clinical classification of IPF patients

\begin{tabular}{ll}
\hline Phenotype & Characteristic hallmarks \\
\hline Familial IPF & $\begin{array}{l}\text { Genetic mutations (e.g. hTERT, hTERC, } \\
\text { surfactant protein genes) } \\
\text { Other organs may be involved }\end{array}$ \\
\hline Slow progressors & $\begin{array}{l}\text { Genetic signature, slow FVC decline } \\
\text { Absence of honeycomb remodeling on CT } \\
\text { scan }\end{array}$ \\
\hline Rapid progressors & $\begin{array}{l}\text { Genetic signature, anti-HSP 70 auto-anti- } \\
\text { bodies; rapid FVC decline }\end{array}$ \\
& $\begin{array}{l}\text { Honeycomb changes and extended disease } \\
\text { on CT scan }\end{array}$ \\
\hline CPFE & $\begin{array}{l}\text { Peculiar function impairment; pulmonary } \\
\text { hypertension; coexisting emphysema }\end{array}$ \\
\hline $\begin{array}{l}\text { MPO-ANCA } \\
+ \text { IPF }\end{array}$ & $\begin{array}{l}\text { Autoantibodies (MPO-ANCA); BAL } \\
\text { eosinophilia; CT: low attenuation areas }\end{array}$ \\
\hline IPF-lung cancer & $\begin{array}{l}\text { Peripheral nodules or masses; peculiar } \\
\text { histologic phenotypes; emphysema }\end{array}$ \\
\hline $\begin{array}{l}\text { IPF-acute } \\
\text { exacerbation }\end{array}$ & $\begin{array}{l}\text { Risk factors: HRCT asymmetry, concomitant } \\
\text { emphysema; DLCO < 47\%; surgery, } \\
\text { pulmonary hypertension }\end{array}$ \\
\hline
\end{tabular}

$\mathrm{CPFE}=$ Combined pulmonary fibrosis and emphysema; $\mathrm{HSP}=$ heat shock protein.

Clinical phenotypes of IPF are reported in table 1. For practical purposes, the need to categorize IPF patients into different subsets with differences in clinical behavior is still unmet; however, clinicians should be aware of the heterogeneity of IPF.

\section{Diagnostic Approach}

Diagnosing IPF in daily practice may be challenging as it requires a multidisciplinary approach and there is often a significant delay between the first manifestation of the disease (typically a combination of dyspnea on exertion and dry cough) and the diagnosis [39]. An early and accurate diagnosis of IPF could be critical for a better outcome as an early therapy could reduce the decline in lung function, especially with the forthcoming advent of new specific treatment for this disease [39]. The previous guidelines [40] using major and minor criteria for the clinical (i.e. nonpathological) diagnosis of IPF have been discarded, as it is now clear that, in an appropriate clinical setting, the presence of a classical UIP pattern on the
HRCT scan is sufficient for a diagnosis of IPF to be made [1], thus obviating the need for a lung biopsy. The classical radiological UIP pattern includes: (1) the presence of subpleural abnormalities, predominantly at the lung bases; (2) reticular abnormality; (3) honeycombing with or without traction bronchiectasis, and (4) the absence of features that are inconsistent with a UIP pattern [upper or middle lobe and peribronchovascular predominance, extensive ground glass abnormality (>reticular abnormality), profuse micronodules, discrete multiple cysts distant from areas of honeycombing, diffuse mosaic attenuation/air trapping or consolidation in bronchopulmonary segment(s)/lobe(s)] [1,41]. The UIP pattern is also characterized by the 'temporal heterogeneity', the alternating areas of normal lung parenchyma with patchy interstitial inflammation, fibrosis and honeycombing. This classification divides patients into different categories of 'diagnostic uncertainty' (definite, possible and inconsistent UIP) and for those individuals with HRCT features of possible or inconsistent types, further diagnostic evaluation (biopsy) is required [1] (table 2). However, this approach leaves a consistent 'gray zone'. CT findings which are not typical of or even inconsistent with UIP require histological analysis [42]. Therefore, guidelines suggest a lung biopsy in these patients, even in those with an HRCT scan without honeycombing but all other UIP features, including traction bronchiectasis. Fell et al. [43] tried to address this problem and showed that increasing age and average total HRCT interstitial score of the chest may predict a biopsy confirmation of IPF. Gruden et al. [44] identified specific HRCT patterns in biopsy-proven UIP cases: classic UIP with honeycombing, fibrosis without honeycombing, minimal fibrosis and ground glass opacity. Fibrosis without honeycombing appeared to be diagnostic of UIP in the proper clinical setting; heterogeneity of the pattern contributed to its specificity.

The clinical decision to perform a surgical lung biopsy should be carefully balanced against the risks, since the risks related to this invasive diagnostic procedure are not negligible, with a 30 -day mortality of about $1.9-16.7 \%$ reported in most studies [45-48]; the risk of mortality is even higher in patients with a histological UIP pattern [46]. A definitive histological diagnosis of the UIP pattern requires: (1) marked fibrosis/architectural distortion with or without honeycombing in a predominantly subpleural/paraseptal distribution; (2) patchy involvement of lung parenchyma by fibrosis, and (3) the presence of fibroblast foci; in addition, the absence of any features considered to be inconsistent with a UIP pattern is also essential [1]. The combination of CT features and histo- 
Table 2. Combination of HRCT and surgical lung biopsy (SLB) for the diagnosis of IPF

\begin{tabular}{lll}
\hline IPF diagnosis & HRCT pattern & SLB pattern \\
\hline Definite & Definite UIP & $\begin{array}{l}\text { UIP definite, UIP probable, UIP } \\
\text { possible, nonclassifiable fibrosis }\end{array}$ \\
\cline { 2 - 3 } & Possible UIP & UIP definite or UIP probable \\
\hline Probable & Possible UIP & $\begin{array}{l}\text { UIP possible or nonclassifiable } \\
\text { fibrosis }\end{array}$ \\
\hline Possible & Inconsistent & UIP definite \\
\hline
\end{tabular}

Adapted from table 6 of ATS/ERS Statement [1].

logical findings generates again different categories of clinical-radiological and anatomical subtypes: definite IPF; probable IPF; possible IPF and finally no IPF (table 2). Probable IPF is the scenario in which CT features are categorized as possible UIP and the histopathology report is possible UIP or nonclassifiable UIP. Possible IPF is when CT features are inconsistent with UIP but histopathologically a UIP pattern is found (table 2). This point is still controversial. These two categories may comprise patients with fibrosing nonspecific interstitial pneumonia or chronic hypersensitivity pneumonitis, or even patients with rarer disorders such as pleuroparenchymal fibroelastosis $[49,50]$ or airway-centered interstitial fibrosis [51]. The differential diagnosis between the UIP-like pattern observed in chronic hypersensitivity pneumonitis and that detected in IPF may be based on the following elements: presence of centrilobular fibrosis, bridging fibrosis and organizing pneumonia in addition to bronchiolitis, granulomas and giant cells [52]. Diagnostic clues derived from the clinical reasoning are not included in the diagnostic approach of current guidelines. Specifically idiopathic nonspecific interstitial pneumonia is an entity that mainly affects nonsmoking women in their 6th decade with an 'autoimmune background' who may develop a full-blown collagen vascular disease during followup $[53,54]$. A typical CT scan feature, which unfortunately does not present in all cases, is sparing of the subpleural regions. Transbronchial lung biopsy is not recommended based on its low-quality evidence, but this point is controversial. Using this method, tiny specimens representing the centrilobular lung parenchyma may be obtained with a low incidence of side effects (mainly pneumothorax) [55]. A variety of morphological patterns may be detectable on these specimens, e.g. granulomas, organizing pneumonia, diffuse alveolar damage or respi-

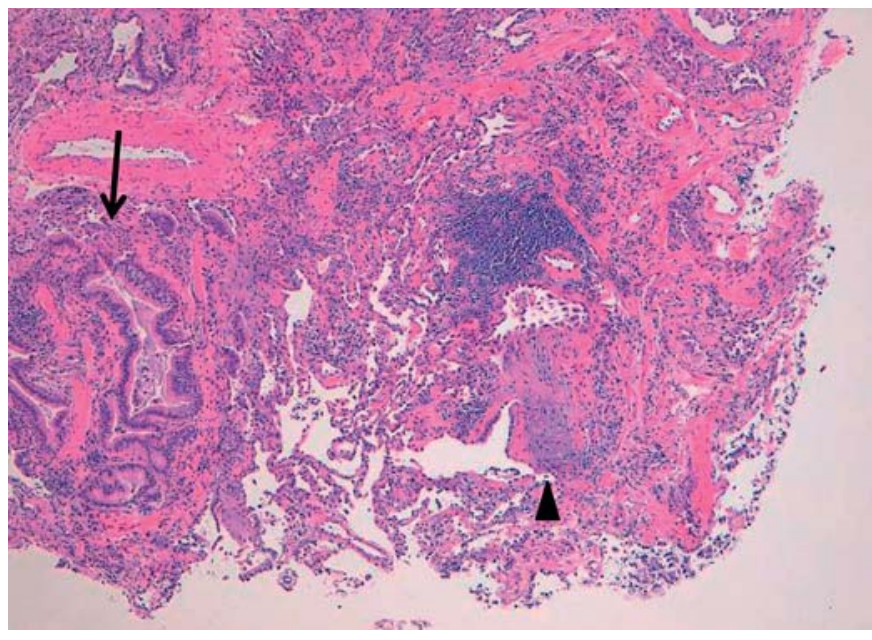

Fig. 2. Lung sample obtained by transbronchial cryobiopsy: wellpreserved lung parenchyma showing honeycomb changes (arrow), fibroblastic foci (arrowhead) and patchy fibrosis (normal lung side by side with fibrotic tissue). All these findings are diagnostic of the UIP pattern (HE; mid-power).

ratory bronchiolitis [56]. Recently, Berbescu et al. [57] suggested that transbronchial lung biopsy might be more useful than previously recognized in confirming UIP. Combinations of interstitial fibrosis in a patchwork pattern along with fibroblastic foci and/or honeycomb changes were considered diagnostic of UIP. Tomassetti et al. [58] highlighted that the UIP pattern in transbronchial biopsy specimens has a high predictive value but also has a low sensitivity (30\%) and a low negative predictive value. Other minimally invasive methodologies, like cryobiopsy, could replace the actual surgical lung biopsy in the near future (although we should be very cautious). Our preliminary unpublished data indicate that the use of cryoprobes eliminates the crushing artifacts and allows to reach the periphery of the secondary pulmonary lobule (fig. 2); furthermore, the interobserver agreement between pathologists for different elementary lesions (i.e. fibroblastic foci, honeycombing or patchy fibrosis) is similar to that previously reported for surgical lung biopsy [59]. Probably in the near future, recognition of peculiar immunohistochemical profiles will increase the specificity of the UIP pattern observed in IPF patients [60]. BAL is useful in excluding other conditions, especially chronic hypersensitivity pneumonitis, which can be suspected when lymphocytosis exceeds 30\% [61]. However, sensitivity and specificity of BAL for the diagnosis of IPF remains unknown, and the use of BAL is discour- 
aged by current guidelines [1]. In the evaluation of suspected IPF, the guidelines recommend the multidisciplinary approach involving interstitial lung disease specialists, radiologists and pathologists [1]. This approach has been shown to improve diagnostic accuracy of IPF and other interstitial lung diseases [62].

\section{Prognostic Evaluation}

The prognosis of IPF is dire, with half of all patients progressing to death from respiratory failure within 3-5 years from initial diagnosis. Results of pulmonary function tests are routinely used as factors predicting survival of IPF patients [63]. A decline in FVC has consistently been shown to be a strong predictor of mortality [64-67] and is frequently used as an end-point in clinical trials. A decline in FVC $\geq 10 \%$ within a 6 -month period is associated with a nearly 5 -fold increase in the risk of mortality $[1,68]$. Both absolute and relative changes in FVC are currently used, but Richeldi et al. [69] recently reported that the relative change in FVC maximizes the chances in identifying a $10 \%$ decline in FVC without sacrificing prognostic accuracy. A milder decline in FVC could have prognostic significance probably when combined with other indicators such as dyspnea [70]. Therefore, agents that attenuate the decline in FVC are anticipated to play an important role in the management of patients with IPF. Other prognostic factors in clinical trials of IPF include DLCO (a decrease $\geq 15 \%$ in the absolute value has been associated with an increased risk of mortality [1]) and a change in alveolar-arterial oxygen tension (a difference $\geq 15 \mathrm{~mm} \mathrm{Hg}$ after 12 months has been shown to be predictive of survival) [70]. The 6-min walk test is widely used in clinical practice. A shorter walk distance and delayed heart rate recovery after this test have been associated with an increased risk of mortality [71]. Pulmonary hypertension and brain natriuretic peptide levels are further independent predictors of survival [72-74].

An important topic in the management of IPF is the staging system. Clinical decisions concerning pharmacological and nonpharmacological treatment and inclusion in a transplant list depend on a considerate estimation of the severity of disease and also on the possibility to predict its prognosis [75], which may be based on pulmonary function tests, FVC and DLCO, for example. A recent study suggests a quite easy clinical staging system (GAP) based on gender, age, FVC (\% of predicted) and DLCO (\% of predicted) to predict mortality up to 3 years [76]. A risk stratification score, which was based on a Medical Research Council Dyspnea Score $>3$, 6-min walking distance $\leq 72 \%$ of predicted and a composite physiologic index $>41$, predicted mortality with high specificity [77].

The overall extent of fibrosis on chest HRCT characterized by a honeycomb pattern and reticulation predict survival [10]. Multiple studies attempted to identify diagnostic and predictive biomarkers of IPF. Until recently, these studies were limited in size and lacked confirmation, but taken together they provided still convincing evidence that changes in blood proteins (e.g. KL-6, SP-A, MMP-7 and CCL-18) or cells (fibrocytes and T-cell subpopulations) are indicative of the presence and outcome of the disease [78-80]. More recently, larger studies have identified gene polymorphisms associated with IPF, as well as protein markers and integrated clinical and molecular prediction rules to predict outcome in patients with IPF [81].

\section{References}

1 Raghu G, Collard HR, Egan JJ, Martinez FJ, Behr J, Brown KK, Colby TV, Cordier JF, Flaherty KR, Lasky JA, Lynch DA, Ryu JH, Swigris JJ, Wells AU, Ancochea J, Bouros D, Carvalho C, Costabel U, Ebina M, Hansell DM, Johkoh T, Kim DS, King TE Jr, Kondoh Y, Myers J, Müller NL, Nicholson AG, Richeldi L, Selman M, Dudden RF, Griss BS, Protzko SL, Schünemann HJ, ATS/ERS/JRS/ALAT Committee on Idiopathic Pulmonary Fibrosis: An official ATS/ERS/JRS/ALAT statement: idiopathic pulmonary fibrosis: evidence-based guidelines for diagnosis and management. Am J Respir Crit Care Med $2011: 15: 788-824$
2 Chilosi M, Doglioni C, Murer B, Poletti V: Epithelial stem cell exhaustion in the pathogenesis of idiopathic pulmonary fibrosis. Sarcoidosis Vasc Diffuse Lung Dis 2010;27:7-18.

3 Chilosi M, Poletti V, Murer B, Lestani M, Cancellieri A, Montagna L, Piccoli P, Cangi G, Semenzato G, Doglioni C: Abnormal re-epithelialization and lung remodeling in idiopathic pulmonary fibrosis: the role of deltaNp63. Lab Invest 2002;82:1335-1345.

$\checkmark 4$ Carloni A, Poletti V, Fermo L, Bellomo V, Chilosi M: Heterogeneous distribution of mechanical stress in human lung: a mathematical approach to evaluate abnormal remodeling in IPF. J Theor Biol 2013;332C:136-140.
5 Vancheri C, Failla M, Crimi N, Raghu G: Idiopathic pulmonary fibrosis: a disease with similarities and links to cancer biology. Eur Respir J 2010;35:496-504.

6 Chilosi M, Poletti V, Rossi A: The pathogenesis of COPD and IPF: distinct horns of the same devil? Respir Res 2012;11:13.

7 American Thoracic Society, European Respiratory Society: American Thoracic Society/ European Respiratory Society International Multidisciplinary Consensus Classification of the Idiopathic Interstitial Pneumonias. Am J Respir Crit Care Med 2002;165:277-304.

$\checkmark 8$ Meltzer EB, Noble PW: Idiopathic pulmonary fibrosis. Orphanet J Rare Dis 2008;3:8-22. 
\$ Navaratnam V, Fleming KM, West J, Smith CJ, Jenkins RG, Hubbard RB: The rising incidence of idiopathic pulmonary fibrosis in the UK. Thorax 2011;66:462-467.

-10 Collard HR, King TE Jr, Bartelson BB, Vourlekis JS, Schwarz MI, Brown KK: Changes in clinical and physiologic variables predict survival in idiopathic pulmonary fibrosis. Am J Respir Crit Care Med 2003;168:538-542.

-11 Kim DS, Collard HR, King TE Jr: Classification and natural history of the idiopathic interstitial pneumonias. Proc Am Thorac Soc 2006;3:285-292.

12 Baumgartner KB, Samet JM, Stidley CA, Colby TV, Waldron JA: Cigarette smoking: a risk factor for idiopathic pulmonary fibrosis. Am J Respir Crit Care Med 1997;155:242-248.

-13 Steele MP, Speer MC, Loyd JE, Brown KK, Herron A, Slifer SH, Burch LH, Wahidi MM, Phillips JA 3rd, Sporn TA, McAdams HP, Schwarz MI, Schwartz DA: Clinical and pathologic features of familial interstitial pneumonia. Am J Respir Crit Care Med 2005; 172:1146-1152.

-14 Marshall RP, Puddicombe A, Cookson WO, Laurent GJ: Adult familial cryptogenic fibrosing alveolitis in the United Kingdom. Thorax 2000;55:143-146.

-15 Lee HL, Ryu JH, Wittmer MH, Hartman TE, Lymp JF, Tazelaar HD, Limper AH: Familial idiopathic pulmonary fibrosis: clinical features and outcome. Chest 2005; 127:20342041.

16 Armanios M: Syndromes of telomere shortening. Annu Rev Genomics Hum Genet 2009; 10:45-61.

$\checkmark 17$ Leslie KO, Cool CD, Sporn TA, et al: Familial idiopathic interstitial pneumonia: histopathology and survival in 30 patients. Arch Pathol Lab Med 2012;136:1366-1376.

18 Selman M, Carrillo G, Estrada A, et al: Accelerated variant of idiopathic pulmonary fibrosis: clinical behavior and gene expression pattern. PLoS One 2007;2:e482.

19 Brown AW, Shlobin OA, Weir N, et al: Dynamic patient counseling: a novel concept in idiopathic pulmonary fibrosis. Chest 2012; 142:1005-1010.

20 Park SO, Seo JB, Kim N, Lee YK, Kim DS: Comparison of usual interstitial pneumonia and nonspecific interstitial pneumonia: quantification of disease severity and discrimination between two diseases on HRCT using a texture-based automated system. Korean J Radiol 2011;12:297-307.

21 Cha SI, Chang CS, Kim EK, et al: Lung mast cell density defines a subpopulation of patients with idiopathic pulmonary fibrosis. Histopathology 2012;61:98-106.

22 Kahloon RA, Xue J, Bhargava A, et al: Patients with idiopathic pulmonary fibrosis with antibodies to heat shock protein 70 have poor prognoses. Am J Respir Crit Care Med 2013; 187:768-775.
23 Gilani SR, Vuga LJ, Lindell KO, et al: CD28 down-regulation on circulating CD4 T-cells is associated with poor prognoses of patients with idiopathic pulmonary fibrosis. PLoS One 2010;5:e8959.

24 Ando M, Miyazaki E, Ishii T, et al: Incidence of myeloperoxidase anti-neutrophil cytoplasmic antibody positivity and microscopic polyangitis in the course of idiopathic pulmonary fibrosis. Respir Med 2013;107:608-615.

25 Cottin V, Nunes H, Brillet PY, et al: Groupe d'Etude et de Recherche sur les Maladies Orphelines Pulmonaires (GERM OP). Combined pulmonary fibrosis and emphysema: a distinct underrecognised entity. Eur Respir J 2005;26:586-593.

26 Ryerson CJ, Hartman T, Elicker BM, et al: Clinical features and outcomes in combined pulmonary fibrosis and emphysema in idiopathic pulmonary fibrosis. Chest 2013, E-pub ahead of print.

27 Park J, Kim DS, Shim TS, et al: Lung cancer in patients with idiopathic pulmonary fibrosis. Eur Respir 2001;17:1216-1219.

28 Kondoh Y, Taniguchi H, Ogura T, et al: Disease progression in idiopathic pulmonary fibrosis without pulmonary function impairment. Respirology 2013, E-pub ahead of print.

9 Cordier JF, Cottin V: Neglected evidence in idiopathic pulmonary fibrosis: from history to earlier diagnosis. Eur Respir J 2013, E-pub ahead of print.

-30 Sverzellati N, Guerci L, Randi G, et al: Interstitial lung diseases in a lung cancer screening trial. Eur Respir J 2011;38:392-400.

-31 Ambrosini V, Cancellieri A, Chilosi M, et al: Acute exacerbation of idiopathic pulmonary fibrosis: report of a series. Eur Respir J 2003; 22:821-826.

32 Song JW, Hong SB, Lim CM, Koh Y, Kim DS: Acute exacerbation of idiopathic pulmonary fibrosis: incidence, risk factors and outcome. Eur Respir J 2011;37:356-363.

33 Tcherakian C, Cottin V, Brillet PY, et al: Progression of idiopathic pulmonary fibrosis: lessons from asymmetrical disease. Thorax 2011;66:226-231.

- 34 Judge EP, Fabre A, Adamali HI, Egan JJ: Acute exacerbations and pulmonary hypertension in advanced idiopathic pulmonary fibrosis. Eur Respir J 2012;40:93-100.

-35 Kondoh Y, Tanigichi H, Katsuta T, et al: Risk factors of acute exacerbation of idiopathic pulmonary fibrosis. Sarcoidosis Vasc Diffuse Lung Dis 2010;27:103-110.

36 Suzuki H, Sekine Y, Yoshida S, et al: Risk of acute exacerbation of interstitial pneumonia after pulmonary resection for lung cancer in patients with idiopathic pulmonary fibrosis based on preoperative high-resolution computed tomography. Surg Today 2011;41:914-921.

37 Cottin V: Clinical year in review: interstitial lung disease. Eur Respir Rev 2013;22:26-32.

38 Akira M, Kozuka T, Yamamoto S, Sakatani M: Computed tomography findings in acute exacerbation of idiopathic pulmonary fibrosis. Am J Respir Crit Care Med 2008;178:372-378.
39 Du Bois RM: An earlier and more confident diagnosis of idiopathic pulmonary fibrosis. Eur Respir Rev 2012;21:141-146.

40 Idiopathic Pulmonary Fibrosis: Diagnosis and Treatment. International Consensus Statement. Am J Respir Crit Care Med 2000; 161:646-664.

41 Hansell DM, Bankier AA, Macmahon H, McLoud TC, Muller NL, Remy J: Fleischner Society: glossary of terms for thoracic imaging. Radiology 2008;246:697-722.

42 Sverzellati N, Wells AU, Tomassetti S, et al Biopsy-proved idiopathic pulmonary fibrosis: spectrum of nondiagnostic thin-section CT diagnoses. Radiology 2010;254:957-964.

$\checkmark 43$ Fell CD, Martinez FJ, Liu LX, et al: Clinical predictors of a diagnosis of idiopathic pulmonary fibrosis. Am J Respir Crit Care Med 2010;181:832.

44 Gruden JF, Panse PM, Leslie KO, Tazelaar HD, Colby TV: UIP diagnosed at surgical lung biopsy, 2000-2009: HRCT patterns and proposed classification system. AJR Am J Roentgenol 2013;200:W458-W467.

45 Kaarteenaho R: The current position of surgical lung biopsy in the diagnosis of idiopathic pulmonary fibrosis. Respir Res 2013;14:43.

46 Blanco M, Obeso GA, Duran JC, Rivo JE, Garcia-Fontan E, Pena E, Rodriguez M, Abort J, Canizares MA: Surgical lung biopsy for diffuse lung disease. Our experience in the last 15 years. Rev Port Pneumol 2013;19:59-64.

47 Utz JP, Rye JH, Douglas WW, Hartman TE, Tazelaar HD, Myers JL, Allen MS, Schroeder DR: High short-term mortality following lung biopsy for usual interstitial pneumonia. Eur Respir J 2011;17:175-179.

48 Blackhall V, Asif M, Renieri A, Civitelli S, Kirk A, Jilaihawi A, Granato F: The role of surgical lung biopsy in the management of interstitial lung disease: experience from a single institution in the UK. Interact Cardiovasc Thorac Surg 2013, E-pub ahead of print.

49 Piciucchi S, Tomassetti S, Casoni G, et al: High resolution CT and histologic findings in idiopathic pleuroparenchymal fibroelastosis: features and differential diagnosis. Respir Res 2011;12:11.

50 Reddy TL, Tominaga M, Hansell DM, et al: Pleuroparenchymal fibroelastosis: a spectrum of histopathologic and imaging phenotypes. Eur Respir J 2012;40:377-385.

51 Churg A, Myers J, Suarez T, et al: Airway-centered interstitial fibrosis: a distinct form of aggressive diffuse lung disease. Am J Surg Pathol 2004;28:62-68.

52 Takemura T, Akashi T, Kamiya H, et al: Pathological differentiation of chronic hypersensitivity pneumonitis from idiopathic pulmonary fibrosis/usual interstitial pneumonia. Histopathology 2012;61:1026-1035.

53 Romagnoli M, Nannini C, Piciucchi S, et al: Idiopathic nonspecific interstitial pneumonia: an interstitial lung disease associated with autoimmune disorders? Eur Respir J 2011;38: 384-391. 
54 Poletti V, Romagnoli M, Piciucchi S, Chilosi M: Current status of idiopathic interstitial pneumonia. Semin Respir Crit Care Med 2012;33:440-449.

55 Poletti V, Patelli M, Poggi S, Bertanti T, Spiga L, Ferracini R: Transbronchial lung biopsy and bronchoalveolar lavage in diagnosis of diffuse infiltrative lung diseases. Respiration 1988;54(suppl 1):66-72.

56 Poletti V, Chilosi M, Olivieri D: Diagnostic invasive procedures in diffuse linfiltrative lung diseases. Respiration 2004;71:107-119.

57 Berbescu EA, Katzenstein AL, Snow JL, Zisman DA: Transbronchial biopsy in usual interstitial pneumonia. Chest 2006;129:11261131.

58 Tomassetti S, Cavazza A, Colby TV, Ryu JH, Nanni O, Scarpi E, Tantalocco P, Buccioli M, Dubini A, Piciucchi S, Ravaglia C, Gurioli C, Casoni GL, Gurioli C, Romagnoli M, Poletti V: Transbronchial biopsy is useful in predicting UIP pattern. Respir Res 2012;13:96.

59 Nicholson AG, Addis BJ, Bharucha H, et al: Inter-observer variation between pathologists in diffuse parenchymal lung disease. Thorax 2004;59:500-505.

60 Chilosi M, Poletti V, Murer B, et al: Abnormal re-epithelialization and lung remodelling in idiopathic pulmonary fibrosis. Lab Invest 2002;82:1335-1345.

61 Ohshimo S, Bonella F, Cui A, et al: Significance of bronchoalveolar lavage for the diagnosis of idiopathic pulmonary fibrosis. Am J Respir Crit Care Med 2009;179:1043-1047.

62 du Bois RM: An earlier and more confident diagnosis of idiopathic pulmonary fibrosis. Eur Respir Rev 2012;21:141-146.

63 Latsi PI, du Bois RM, Nicholson AG, Colby TV, Bisirtzoglou D, Nikolakopoulou A, Veeraraghavan S, Hansell DM, Wells AU: Fibrotic idiopathic interstitial pneumonia: the prognostic value of longitudinal functional trends. Am J Respir Crit Care Med 2003;168:531537.
64 du Bois RM, Weeycher D, Albera C, et al: Ascertainment of individual risk of mortality for patients with idiopathic pulmonary fibrosis. Am J Respir Crit Care Med 2011;184:459466.

65 Cottin V: Changing the idiopathic pulmonary fibrosis treatment approach and improving patient outcomes. Eur Respir Rev 2012;21: 161-167.

66 Du Bois RM, Weycker D, Albera C, et al: Sixminute-walk test in idiopathic pulmonary fibrosis test validation and minimal clinically important difference. Am J Respir Crit Care Med 2011;183:1231-1237.

67 Wells AU, Behr J, Costabel U, Cottin V, Poletti V, Richeldi L: Hot of the breath: mortality as a primary end-point in IPF treatment trials: the best is enemy of the good. Thorax 2012;67:938-940.

68 Ley B, Ryerson CJ, Vittinghoff E, Ryu JH, Tomassetti S, Lee JS, Poletti V, Buccioli M, Elicker BM, Jones KD, King TE Jr, Collard HR: A multidimensional index and staging system for idiopathic pulmonary fibrosis. Ann Intern Med 2012;156:684-691.

69 Richeldi L, Ryerson CJ, Lee JS, Wolters PJ, Koth LL, Ley B, Elicker BM, Jones KD, King TE Jr, Ryu JH, Collard HR: Relative versus absolute change in forced vital capacity in idiopathic pulmonary fibrosis. Thorax 2012;67: 407-411.

70 Collard HR, King TE Jr, Bartelson BB, et al: Changes in clinical and physiologic variables predict survival in idiopathic pulmonary fibrosis. Am J Respir Crit Care Med 2003; 168 : 538-542.

71 Caminati A, Bianchi A, Cassandro R, et al: Walking distance on 6-MWT is a prognostic factor in idiopathic pulmonary fibrosis. Respir Med 2009;103:117-123.

72 Kimura M, Tanigichi H, Kondoh Y, et al: Pulmonary hypertension as a prognostic indicator at the initial evaluation in idiopathic pulmonary fibrosis. Respiration 2013;85:456463.
73 Caminati A, Harari S: IPF: new insight in diagnosis and prognosis. Respir Med 2010; 104(suppl 1):S2-S10

74 Song JW, Song JK, Kim DS: Echocardiography and brain natriuretic peptide as prognostic indicators in idiopathic pulmonary fibrosis. Respir Med 2009;103:180-186.

75 Flaherty KR, Mumford JA, Murray S, Kazerooni EA, Gross BH, Colby TV, Travis WD, Flint A, Toews GB, Lynch JP 3rd, Martinez FJ: Prognostic implications of physiologic and radiographic changes in idiopathic interstitial pneumonia. Am J Respir Crit Care Med 2003; 168:543-548.

76 Du Bois R, Albera C, Bradford W, Costabel U, Hormel P, Lancaster L, Noble PW, Sahn SA, Szwarcberg J, Thomeer M, Valeyre D, du Bois RM, INSPIRE Study Group: Percent predicted forced vital capacity (FVC) is a reliable, valid, and responsive measure of clinical status in patients with idiopathic pulmonary fibrosis (IPF). Eur Resp J 2010;36(suppl 54): 646s.

77 Mura M, Porretta MA, Bargagli E, et al: Predicting survival in newly diagnosed idiopathic pulmonary fibrosis: a 3-year prospective study. Eur Respir J 2012;40:101-109.

78 Vij R, Noth I: Peripheral blood biomarkers in idiopathic pulmonary fibrosis. Transl Res 2012;159:218-227.

79 Richards TJ, Kaminski N, Baribaud F, et al: Peripheral blood proteins predict mortality in idiopathic pulmonary fibrosis. Am J Respir Crit Care Med 2012;185:67-76.

-80 Zhang Y, Kaminski N: Biomarkers in idiopathic pulmonary fibrosis. Curr Opin Pulm Med 2012;18:441-446.

81 Yang IV, Luna LG, Cotter J, et al: The peripheral blood transcriptome identifies the presence and extent of disease in idiopathic pulmonary fibrosis. PLoS One 2012;76:e37708. 